\title{
A Trio of Courses to Support Mathematics Transfer Students' Development of Professional Vision
}

\author{
Sarah A. Roberts ${ }^{1 *}$ (D), Hannali Pajela ${ }^{1}$ (D) \\ 1 University of California, Santa Barbara, USA
}

Received 9 November 2021 - Accepted 19 January 2022

\begin{abstract}
This study explored the development of professional vision as related to transfer students becoming upper division, four-year mathematics students. We drew from qualitative focus groups with 21 participants at a four-year research university, who were enrolled in a trio of concurrent transitional mathematics courses. We examined the development of professional vision in three areas: engaging in proof and problem solving, being a member of a university mathematics community, and finding a future in mathematics. We found that students developed professional vision related to proof and problem solving, including experiences that were more abstract, more proof-based, and more problem solving-based. Development of community as part of the students' professional vision was embedded throughout the cohort model, a noteworthy aspect of the trio of courses. Finally, students' professional vision around finding a future in mathematics developed around future careers in mathematics, as well as students' access to and knowledge of future career opportunities. Ultimately, diminished timelines exacerbated many of students' struggles, as related to professional vision or otherwise.
\end{abstract}

Keywords: transfer students, professional vision, college mathematics, transitional mathematics courses

\section{INTRODUCTION}

A key bridge to supporting the United States' science, technology, engineering, and mathematics (STEM) workforce is understanding the transfer pipeline of STEM majors from community colleges to four-year universities. Currently, we have very little, if any, research about how to support mathematics majors, in particular, as they make the transition from two-year institutions to four-year institutions of higher education. While there is more general scholarship about transfer students (e.g., Melguizo et al., 2011), there is far less written about the unique experiences of undergraduate transfer mathematics students from community colleges to four-year universities. Not only must transfer mathematics students face the transfer student experience, they also face another transition: the transition to proof and higher-level mathematics. These experiences and activities at universities are starkly different from their prior schooling experiences (Moore, 1994). Even with many universities offering transfer to proof classes, this content remains a significant challenge for students (e.g., Thoma \& Nardi, 2017) and a barrier to their retention.

The university that was the site of this study, like probably many other universities, has seen a high attrition of transfer students from its mathematics major. To attend to this attrition, the university created a trio of courses to support student retention in the mathematics major. This study qualitatively examined whether these courses supported students' development of mathematics professional vision (Goodwin, 1994) to support such student retention. Our study focused on transfer students in mathematics, where research is currently lacking about transfer students. Our research question was: How did transfer mathematics students develop professional vision to become upper division, four-year mathematics students? In conjunction with this question, we discuss some of the struggles novice transfer mathematics students faced as they developed professional vision. 


\section{Contribution to the literature}

- Studies mathematics transfer students at a research university engaged in trio of courses. There is currently very little research on mathematics transfer students.

- Seeks to understand student experiences of this trio of courses through the use of focus groups and qualitative analyses.

- Uses a professional vision framework to understand and flesh out the students' experiences in the courses in light of data and current literature.

\section{FRAMEWORK}

We used Goodwin's (1994) professional vision as a conceptual framework to consider mathematics transfer students' development in their dual roles of being fouryear college students and being upper-level mathematics students.

Professional vision is the socially organized practices that members use to understand and see the events that are of interest to a particular group (Goodwin, 1994). Goodwin (1994) explained that

Discursive practices are used by members of a profession to shape events in the domains subject to their professional scrutiny. This shaping creates the objects of knowledge that become the insignia of a profession's craft: the theories, artifacts, and bodies of artifacts that distinguish it from other professions (p. 606).

For example, Goodwin (1994) explained that an architect and a farmer would see a patch of dirt very differently. In this study, we were interested in how the transfer students were helped to make sense of the professional vision necessary for being four-year mathematics students. For example, as a student moved from being a mathematics student at a community college to being a mathematics student at a four-year university, what would be the practices and domains associated with members in a mathematics department?

For students, who are the "experts?" Are they those students who are about to graduate? How would a new transfer student be a mathematics student compared to one ready to graduate? In terms of being a mathematics student, they would view the ways of being a student very differently.

Goodwin (1994) noted that professional vision is socially constructed and not socially culturally neutral, which Louie (2018) has recently reiterated in her work. This means that professional vision occurs within interactions with other individuals; participating in these practices also determines what counts as important to a particular social group. Therefore, the students in our study interacted with other students, faculty, and graduate students as part of their work to develop professional vision within the mathematics department. Additionally, through this participation in social practices, individuals who are part of these groups learned what it meant to become competent members of a social group - learning what counted and what did not count as competent participation through their participation in actual practice (Gravengaard \& Rimestad, 2012). For example, college mathematics students learned how to do proofs in an introduction to proof course. This helped them learn what counted as competent practice in the completion of proofs and perhaps more, such as giving feedback to peers on their proof (and getting feedback from peers and faculty) and developing community around mathematical problem solving.

Experts support novices' development of this professional vision. For example, Grossman et al. (2009) found that instructional coaches' feedback helped novices understand complex instructional practice; coaches needed professional vision to help novices see instructional features during this coaching. Similarly, in a mathematics department, professors, graduate students, advisors, and fellow undergraduates play key roles in providing new members of the community, or novices, with information about what it means to be part of a community and what competent practice entails.

Transfer students pursuing a mathematics major are confronted with myriad difficulties upon matriculating to a four-year university - tied to struggles stemming from making an important transition in their mathematical development, being unfamiliar with a new environment (i.e., place, expectations, etc.), and having to think of their quickly approaching post-graduate plans. We used a framework of professional vision for our examination of transfer mathematics students as they developed into upper-division mathematics students.

\section{LITERATURE REVIEW}

Our literature review examines prior studies around professional vision. Additionally, while there is little work on mathematics transfer students, particularly related to professional vision, we provide background information on the transfer student experience, as well as upper-level mathematics student needs. 


\section{Professional Vision}

Much of the work around professional vision has used a lens of noticing (e.g., Sherin \& van Es, 2009) to examine the practices of preservice or in-service mathematics teachers as they watch videos of a teacher's mathematics instruction. A facilitator asks the teacher, "What do you notice?" (Sherin \& van Es, 2009, p. 27), and the authors and/or participants analyze videos of classroom practices, discussing such topics as reasoning strategies. Santagata et al. (2021) reviewed 35 mathematics teacher noticing papers written in the past two decades, illustrating that this is a popular frame of reference currently for research in mathematics education when using video and the frame of noticing and professional vision.

Other subject areas have also adopted professional vision for their work, such as architecture, fingerprint examination, and newspaper writing. Within architecture, Styhre (2009) described the importance of professional vision in being able to visually examine and inspect sites, to find architectural solutions to problems, and to make contributions to a given environment. These are all aspects of an architect's professional vision. With regards to fingerprint examination, Mustonen and Hakkarainen (2015) studied two novice fingerprint analysts, how their fingerprint professional vision developed, and how they reflected on their developing performance. This study was actually useful as we considered the development of our novice mathematics students and their development of mathematics professional vision, because our methodology mirrored Mustonen and Hakkarainen's (2015), in that we asked for the students to reflect on their development of professional development through their participation in focus groups and interviews, similar to how these researchers had their participants reflect through interviews and diaries. Finally, Gravengaard and Rimestad (2012) described the development of journalists' development of professional vision through their participation in daily newsroom meetings. Journalists had to decide what constituted what counted as a good news story. This process was similar to the work that mathematics students complete in their upper division classroom practice, where they learn what counts as a good proof, as we explored. These studies on professional vision, while outside of the realm of college mathematics, provided a foundation for the professional vision of college transfer students that we study here.

\section{Transfer Student Needs}

This study was conducted in the United States, but the findings can be applied to other contexts. On the broadest scale, transfer students are often composed of minoritized and nontraditional students, so successful support systems can be useful across the board to all students but are of utmost importance to these populations. When considering transfer students specifically, it should be noted that community colleges have counterparts globally - e.g., tertiary and further education colleges (TAFEs) in Australia, polytechnic institutes in Canada, and technical colleges in the UK. Different institutions may vary in how they function, but there is an increased international interest in structuring pathways from community colleges and their global counterparts to universities to broaden the accessibility of higher education (Raby et al., 2016). Additionally, for mathematics specifically, other countries recognize the difficulties of bridging to university-level mathematics and have conducted similar studies on supports (e.g., Gordon \& Nicholas, 2013). Within the context of this study, we note that understanding transfer mathematics students' needs and supports is informative in other broader contexts.

Community colleges play an important role in the United States' postsecondary education. Though community colleges offer terminal associate degrees, the importance of bachelor's degrees has driven many students to take general education classes at community colleges with the intention of transferring to four-year universities. The lower cost, proximity to home, and flexible schedules that allow for simultaneous part- and even full-time work make community colleges an appealing and accessible option for students (Mattis \& Sislin, 2005). As such, the community college population has higher percentages of female, Black or Latinx, and low-income students than four-year universities (Provasnik \& Planty, 2008). Understanding transfer students and their needs is an important part to supporting historically underrepresented and underserved groups in STEM fields.

Transferring and adapting to a four-year institution can be complex, requiring adjustments from academic to environmental to psychological. Unlike most community college experiences, classroom instruction is not the only mandate of their professors, who also need to engage in scholarly activity and academic service (Laanan, 2001; Townsend \& Wilson, 2006). This culture change often results in a phenomenon known as "transfer shock" (Hills, 1965), characterized by a transient drop in GPA after transferring to a four-year university (Laanan, 2001; Townsend \& Wilson, 2006). Difficulties frequently extend beyond academic performance, with transfer students reporting feelings of alienation and isolation (Reyes, 2011).

Customized orientations, advising, mentoring, and undergraduate research can be effective in improving the performance and sense of belonging of STEM transfer students (Scott et al., 2015). Building an academic environment, where students feel encouraged to approach their instructors can result in a better adjustment at a university, as positive student-faculty interactions have helped STEM students to develop a stronger and more positive perception of their academic 
goals and intellectual development (Lopez \& Jones, 2017). Developing peer connections has also created a support system that resulted in higher persistence and improved performance (Matthews, 1996), highlighting the importance of sense of belonging and community for students' identity for minoritized students in the STEM fields in achieving success at both the undergraduate and graduate levels (Smith, 2016).

\section{Upper-Level Mathematics Student Needs}

Being an upper-level mathematics student has its own unique challenges, which can be exacerbated when content shifts to being more proof-based. With transfer students' prior mathematical experiences being largely centered around computation and application of the theorems and formulas, the transition to proof-based mathematics can be challenging and abrupt (Moore, 1994). Mathematics departments and scholars have designed and assessed the effectiveness of introduction to higher mathematics classes, mathematics seminars (Levine \& Shanfelder, 2000), and transition to proof courses (David \& Zazkis, 2020). Still, difficulties surrounding learning how to construct and write proofs persist (e.g., Brown, 2017). The literature notes two specific ways of supporting mathematics students through this transition to proof-bridge programs (Gordon \& Nicholas, 2013) and seminars (Polhill, 2007). Both focus on skills important to being mathematics students, with the bridge programs more content focused and seminars largely introducing students to advising and career options.

Mathematics students, in addition to their work with proof, must also transition to life after college (e.g., professional life, graduate school, etc.). There is little research about what post-mathematics major life involves. In the available research, Piotrowski and Hemasinha (2012) found that, overall, approximately one-quarter of participating students plan to work fulltime after graduation, with around 55\% finding a job in mathematics and attending graduate school simultaneously, and one-fifth planning to obtain a graduate degree full-time. This study uses a professional vision framing to understand how transfer mathematics students developed professional vision to become upper division, four-year mathematics students.

\section{METHOD}

\section{Study Context}

This study took place at a minority-serving research university in California-a Hispanic-serving and an Asian American and Native American Pacific IslanderServing Institution. The university had a total enrollment of approximately 23,800 students in 2017-18, with approximately 21,000 undergraduates and 2,700 graduate students. Across the campus, the ethnic/racial breakdown was reported as follows: $1 \%$ American Indian/Alaskan, 5\% Black/African American, 29\% Chicano/Latino, 28\% Asian/Pacific Islander, and 36\% White.

The context of this study was a three-course trio of mathematics courses for transfer students. Henceforth, we will refer to the courses composing the trio of courses as Course A, Course B, and Course C. Both Course A and Course B were offered exclusively to transfer students. Course A was a special topics course that covered myriad topics and was relatively flexible content-wise. Dr. Blanco was the instructor of Course A and the developer of the three-course sequence. She explained that Course A students mostly worked in groups and presented problems in class, solving word problems, instead of computational problems. Students got a lot of feedback from Dr. Blanco, where the goals of the course were making students aware of how a mathematician works, providing them feedback on their work, and making them aware of the expectations that their upperdivision course professors were going to have for them.

The undergraduate mathematics advisor, Ms. Nemet, was the instructor of Course B. This course primarily informed transfer students of campus, department, and career resources. Ms. Nemet described this course as a "resource-based" course, in that its goal was to help students make a smoother transition from the community college to the research university. The course introduced students to the "abundance of resources" that the university had to offer to better acclimate them to the university and their major. Students had assignments, like going to office hours, finding resources the university had to offer, and attending university career counseling services.

Course $\mathrm{C}$ was a prerequisite for upper division mathematics courses and was an introduction to the elements of propositional logic, techniques of mathematical proof, and fundamental mathematical structures, including sets, functions, and relations. This class acted as a gatekeeping class for the mathematics major. Furthermore, some transfer students left the university completely following this course. While there were multiple sections of Course C, during this year, there was only one section for transfer students in the trio of courses, with Dr. Olson teaching the section. Dr. Olson noted that in his teaching of the course, his goal was for students to know how to write a proof statement, to know how to analyze the structure of the statement, to strategize on a particular proof technique that they wanted to use, and then to be able to write a cohesive, comprehensive, and well-written argument as to why that statement was true. Dr. Olson taught his section of Course $\mathrm{C}$ using set theory, functions, and relations as the grounding content, but that content was really the avenue for students to develop a solid understanding of proof. 
The mathematics department had previously offered courses for transfer students, but the year of this study was the first year they offered all three courses concurrently and as a cohort model. Students were chosen to participate in the trio of courses by their favorable grades in community college mathematics courses.

\section{Participants}

Dr. Blanco assisted us in recruiting 21 undergraduate transfer students to participate in focus groups. All participants were individuals who took the trio of courses for transfer students (nine females and 12 males) during Fall 2018. Eighteen of the participants were mathematical science majors and three were applied mathematics majors. We did not collect ethnographic data from participants.

\section{Data Collection}

Following a class session of Course A, we divided participants into three, randomly assigned, semistructured focus groups (Yin, 2016), splitting participants evenly between three interviewers. Within this paper, we label these three focus groups as FG1, FG2, and FG3. Our interview focus group questions attended to how the transfer mathematics students developed professional vision through their participation in the trio of courses and what struggles were associated with students' participation in the trio of courses for transfer mathematics students, asking questions about: students' experiences in the trio of courses, students' experiences being transfer students, students' ways of thinking about and doing mathematics, and students' preparation for a career in mathematics.

\section{Data Analysis}

All focus groups were audio recorded and transcribed verbatim. We used pseudonyms for the participants and the courses. The authors initially used descriptive open coding to identify the contents of and to create categories for the data (Saldaña, 2016), looking for examples of students' ideas of their own development of professional vision. We coded the data independently, reconciling our individual codes. We agreed upon codes related to professional vision of fouryear students and their work in upper-division mathematics courses: proof and problem solving, community, and future as a mathematician (as the three domains of professional vision that we agreed that mathematics transfer students needed to develop through their transfer to a four-year university). The authors then pair-coded the corpus of the data, coding the data independently, discussing the coding, and reconciling any differences. Once all data was pair coded and discussed, we looked within and across each category of data to examine consistencies and inconsistencies relating to the research question. We developed themes within each code, which we share within the findings (Miles et al., 2020). We wrote analytic memos to track our research processes, to develop our ideas, and to test our conjectures throughout the data collection and analysis process (Yin, 2016).

\section{FINDINGS}

Using a professional vision conceptual framework, we considered how transfer mathematics students developed professional vision in three areas: engaging in proof and problem solving, being a member of a university mathematics community, and finding a future in mathematics.

\section{Engaging in Proof and Problem Solving}

The development of mathematical skills and experiences was clearly the key foci of these three courses. Students explained that this mathematics: (a) was different from their experiences in community college, in that it involved more abstract and proof-based mathematics compared to a previous computational focus; (b) was more steeped in problem solving compared to prior solution-based strategies; (c) was more proof-based and required more problem solving, which was beneficial, not only for their current coursework, but also for their future careers; and (d) was supported through the work in Course A (the special topics course, which supported Course C, the standard transition to proof course) through its problem solving approach. These four aspects contributed to students' professional vision as mathematics students, particularly, those aspects related to proof and problem, which they would need in upper-division courses for the major.

Students in the trio of courses did not necessarily view the mathematics done at the community college level as "real math." Students felt like they were in the midst of a "complete shift" (Kacey, FG3, 837-838), they went from "performing calculations" to engaging in mathematics at the university that was "more abstract" (Seth, FG2, 638-640). Therefore, this more developed sense of mathematics became part of their professional vision as mathematics students.

Mathematics previously had not necessarily required constructing meaning or making connections. Fouryear-university mathematics now involved new types of proficiencies. Students began to develop problem solving-based strategies. Antonio shared that these new proficiencies and connections helped him see, "strategies we have to solve different problems and, also, on confronting getting stuck...how to deal with that" (FG1, 263-266). Meaning-making and problem solving in higher-level mathematics held much more importance at the university as part of students' professional vision. 
Fifteen of the 22 students explicitly expressed that completing these courses developed knowledge and skills that would prepare them for future coursework, an indication of their burgeoning professional vision related to proof and problem solving. As Li revealed, "I didn't really know how to write proofs until the bundle of classes, so I feel that is something that's super integral in upper division courses" (FG2, 211-212). Kacey also illustrated that these problem-solving skills would be useful in any STEM job: "I think any STEM job requires you to just think on your feet and not just critical thinking...problem solving" (FG3, 657-660). Professional vision related to proof and problem solving would allow students to write proofs and engage in general critical thinking in the workforce.

While students developed an understanding in proof, they found discrepancies between acceptable proof structures in Course A and Course C. Michael shared, "Dr. Blanco...is strict... The proof may be right, but if it is not structured...then it is not going to be accepted in next quarter or the next quarters" (FG3, 250-253). Dr. Blanco endeavored to prepare students to write proofs in a particular way, but students found that, "Course C, there's, I think, more of a leniency on the structure...like, 'Oh, you have to write complete sentences and complete paragraphs'" (Li, FG2, 229-231). Dr. Blanco required more than just the mathematical argument of the proof, while Dr. Connor was more lenient in this regard. That said, with Dr. Blanco's higher expectations came more opportunities to hone and improve skills with constant feedback, allowing room for corrections. In the development of professional vision, there was not a universal standard in the department upon what was necessary for proof structure for students as they moved to upper division courses.

\section{Being a Member of a University Mathematics Community}

Development of community was embedded throughout the trio of courses cohort model. Students took all courses during the same term, likely only taking one additional university course during their first term during this study. The trio of courses provided students an opportunity to connect with other students and to develop a mathematics community. Katie shared: "I also like how we have class with all the same people...because it's such a good resource to help you when you need it...now we're like each other's friends" (FG1, 95-100). These courses created an almost readymade community, as students spent most of their school-time together. Community became, for many students, an aspect of the four-year mathematics students' professional vision.

Many participants, additionally, lived together in transfer student housing, providing a close, cohesive, intimate first quarter on campus. Living nearby the university was especially convenient, because, as Sasha noted: "I feel like that helps with forming study groups, because we run into each other" (FG3, 356-357).

Not all students felt this embracing warmth of community within the trio of courses. Students who did not live in transfer student housing had a slightly different experience. For instance, a commuter student noted, "[A] challenge I had this quarter...I commute here, so there is a certain time I can be here. Because, the bus leaves" (Rick, FG3, 521-523). While community was seemingly important for most participants as part of their professional vision, it was critical to recognize how the trio of courses community acted as a significant support system. Students were anxious about how to survive after having so much support their first term, as this community was more tenuous after the first term once the trio of courses ended. It was unclear how the end of the trio of courses would affect students' professional vision and their community.

\section{Finding a Future in Mathematics}

We identified three themes related to four-year mathematics students' professional vision around finding a future in mathematics: (a) students' future careers in mathematics; (b) students' access to campus suggested resources for future careers; and (c) students' access to and knowledge of future career opportunities. The trio of courses opened possibilities for transfer students' futures in mathematics. The trio of courses provide important support for students' development of professional vision related to their future in mathematics, which was important, as others have found that students can find that their mathematics degrees are limiting, beyond a career in teaching (e.g., Stage \& Maple, 1996). During Course B, the advising course, students learned how to apply to graduate programs, what graduate school might entail, and what possible careers were available. The Course B instructor, the advisor, sent out weekly emails about job opportunities, internships, and upcoming panels. These resources provided students with a sense of possible future opportunities and what it would take to get there and helped students to shape professional vision with regard to their future in mathematics. For example, Sophia shared: "Before [Course B], I knew nothing about what I would [need to] do to go to grad school" (FG3, 385). Even with the support of the trio of courses, many students felt behind as they considered their futures in mathematics, particularly with regards to securing internships and conducting research with professors. Sasha described her concerns:

I struggled with feeling...we come in...juniors, and then two years, and then you are done...I just feel like it is a lot in a short amount of time...in [Course B], it was great, we talk [about] careers and grad school, and then I am, like, dang, I just 
got here [Laughter and agreeance from others.] (FG3, 501-506).

Participants' timelines were sped up compared to non-transfer students, and their options for taking advantage of opportunities on campus and beyond were limited. Everything, including professional vision, was compressed when a student was a transfer student.

\section{DISCUSSION}

Transfer students in a trio of courses in a US mathematics department developed professional vision (Goodwin, 1994) in several contexts. They learned proofs and problem solving beyond procedural fluency, while fostering community and considering their future careers. Students developed significant rapport with fellow peers, socially constructing their professional vision. The community created within the trio of courses aided both academic and social adjustment related to multiple facets of students' identities as university students and mathematics majors, and the courses helped participating students understand what counted as competent participation through partaking in such activities as proof writing, study groups, and graduate school panels (Gravengaard \& Rimestad, 2012).

Most students felt that the trio of courses supported them in their development as upper division four-year mathematics transfer students. However, there were still some struggles that persisted, the biggest being condensed timelines. This condensed timeline affected everything from acquiring proficiency in proofs and problem solving to integrating themselves into the community (academically and socially) to work towards their future careers. A transfer student's limited timeline exacerbated seemingly every other struggle. The transfer students were forced to navigate through some of these struggles, like their coursework, at an accelerated pace given their limited time. The cohort-style was a noteworthy aspect of the trio of courses, with students repeatedly expressing how the smaller class size with the same classmates allowed them to make meaningful relationships. The cohort provided a place for students to develop expertise and professional vision (Goodwin, 1994) around the work of being a mathematics student and the work of proof and problem solving. This effect was further amplified by many trio students living together in transfer student housing. Jacobson et al. (2017) similarly found that transfer housing helped retain transfer students. Socially and academically integrated community may have retention benefits, as the transfer students felt a greater sense of belonging (Yosso et al., 2009).

\section{Implications}

The high attrition rate of transfer students was not unique to this university, with studies estimating only $27 \%$ of first-time, full-time, to-public-school transfer students obtain their bachelor's degree within six years of enrollment (National Center for Education Statistics, 2020). We provide promising insights, uncovering specific ways that community manifested itself - for instance, the combined cohort-structure and transfer student housing that benefitted transfer students' sense of belonging and community. Moreover, we contribute to the relatively sparse research on transfer students in mathematics, and our framework was useful in understanding the mathematics transfer student experience. Using professional vision (Goodwin, 1994) as a lens, we found that the supports inherent to the trio of courses were generally successful in helping students grapple with their first upper division course and their first term at the university.

Understanding undergraduate mathematics students' development of professional vision helps fouryear mathematics departments and universities develop better course sequences and advising for students. This research can also influence community college and fouryear partnerships that could bolster students' transitions to universities, heading off some of the challenges that students described in this paper. The transfer pipeline continues to be an economical and viable pathway for students to obtain their undergraduate degrees from four-year universities. A diverse STEM workforce is essential-for the economy, for the distinct strands of research that diverse scientists can study and discover, and because we should demand equity on principle alone (Melguizo et al., 2010) - and transfer students and community colleges can contribute to this diverse STEM workforce. The earlier students are aware of resources and can maximize their engagement with experiences (i.e., research, jobs, internships, etc.), the better equipped they will be able to make the most of their time at their new universities.

\section{Limitations and Future Research}

We were limited to students' verbal comments from a fixed moment in time, had no opportunities to observe the students, such as in the trio of courses, and lacked comparative groups, such as transfer students not enrolled in the trio of courses or non-transfer students in Course C. In the future, we will develop comparative groups of transfer students not in the trio of course, as well as non-transfer students, and we will develop observations and surveys to implement across the year. While we recognize how we could develop our study further, we believe we collected data that provided an important illustration given our current limited understanding of transfer mathematics students. Future research can address these limitations and investigate other related questions. While the trio of courses created a sense of belonging among transfer students, future studies could investigate successive terms and/or years to consider when support is reduced or removed. 


\section{Considerations for Practice}

The courses discussed in this study were not unique on their own (e.g., Polhill, 2007). However, these courses add to existing literature because of courses' concurrent use as a cohort model. Students repeatedly noted the strength of the trio of courses. Taking courses with one another, getting to know each other, and feeling comfortable enough to ask each other for help was important. Finally, many students had the opportunity to live with each other in transfer student housing. For those students who had this opportunity to live in transfer housing, there was easy access to study groups and community. If universities have the ability, it seems that this cohort model was the greatest strength of the work that occurred.

\section{CONCLUSIONS}

Time is not on transfer students' side. Transfer students repeatedly shared that their diminished timelines exacerbated many of their struggles, from developing a sense of belonging to grappling with content material. Structuring cohort-style courses and informing students of their resources is one pathway forward to facilitating students' professional vision.

Author contributions: All authors have sufficiently contributed to the study, and agreed with the results and conclusions.

Funding: This research was funded by the UCSB Academic Senate and UCSB ISBER Collaborative Research Initiative.

Declaration of interest: No conflict of interest is declared by authors.

\section{REFERENCES}

Brown, S. A. (2017). Who's there? A study of students' reasoning about a proof of existence. International Journal of Research in Undergraduate Mathematics Education, 3(3), 466-495. https://doi.org/10.1007/ s40753-017-0053-6

David, E. J., \& Zazkis, D. (2020). Characterizing introduction to proof courses: A survey of US R1 and R2 course syllabi. International Journal of Mathematical Education in Science and Technology, 51(3), 388-404.

Goodwin, C. (1994). Professional vision. American Anthropologist, 96(3), 606-633. https://doi.org/ 10.1525/aa.1994.96.3.02a00100

Gordon, S., \& Nicholas, J. (2013). Students' conceptions of mathematics bridging courses. Journal of Further and Higher Education, 37(1), 109-125. https: / / doi.org/10.1080/0309877X.2011.644779

Gravengaard, G., \& Rimestad, L. (2012). Elimination of ideas and professional socialisation: Lessons learned at newsroom meetings. Journalism Practice, 6(4), 465-481. https://doi.org/10.1080/17512786. 2011.642243
Grossman, P., Hammerness, K., \& McDonald, M. (2009). Redefining teaching, re-imagining teacher education. Teachers and Teaching: Theory and Practice, 15(2), 273-289. https://doi.org/10.1080/ 13540600902875340

Hills, J. R. (1965). Transfer shock: The academic performance of the junior college transfer. The Journal of Experimental Education, 33(3), 201-215. https: / / doi.org/10.1080/00220973.1965.11010875

Jacobson, T., Delano, J., Krzykowski, L., Garafola, L., Nyman, M., \& Barker-Flynn, H. (2017). Transfer student analysis and retention: A collaborative endeavor. Reference Services Review, 45(3), 421-439. https:/ / doi.org/10.1108/RSR-10-2016-0069

Laanan, F. S. (2001). Transfer student adjustment. New Directions for Community Colleges, 2001(114), 5-13. https:// doi.org/10.1002/cc.16

Levine, A., \& Shanfelder, B. (2000). The transition to advanced mathematics. Problems, Resources, and Issues in Mathematics Undergraduate Studies, 10(2), 97-110.

https:// doi.org/10.1080/10511970008965951

Lopez, C., \& Jones, S. J. (2017). Examination of factors that predict academic adjustment and success of community college transfer students in STEM at 4year institutions. Community College Journal of Research and Practice, 41(3), 168-182 https:/ / doi.org/10.1080/10668926.2016.1168328

Louie, N. L. (2018). Culture and ideology in mathematics teacher noticing. Educational Studies in Mathematics, 97(1), 55-69. https://doi.org/10.1007/s10649-0179775-2

Matthews, R. (1996). Learning communities: A retention strategy that serves students and faculty. American Association of State Colleges and Universities.

Mattis, M. C., \& Sislin, J. (2005). Enhancing the community college pathway to engineering careers. National Academies Press.

Melguizo, T., Kienzl, G. S., \& Alfonso, M. (2011). Comparing the educational attainment of community college transfer students and four-year college rising juniors using propensity score matching methods. The Journal of Higher Education, 82(3), 265-291. https://doi.org/10.1080/00221546. 2011.11777202

Miles, M. B., Huberman, A. M., \& Saldaña, J. (2020). Qualitative data analysis: A methods sourcebook. SAGE.

Moore, R. C. (1994). Making the transition to formal proof. Educational Studies in Mathematics, 27(3), 249266. https:/ / doi.org/10.1007/BF01273731

Mustonen, V., \& Hakkarainen, K. (2015). Tracing two apprentices' trajectories toward adaptive professional expertise in fingerprint examination. 
Vocations and Learning, 8(2), 185-211. https:/ / doi.org/10.1007/s12186-015-9130-7

National Center for Education Statistics. (2020). The Condition of Education 2020 (NCES 2020-144). https:/ / nces.ed.gov/programs/coe/pdf/coe_ctr. pdf

Piotrowski, C., \& Hemasinha, R. (2012). Career path decisions of masters-level mathematics students: A comparative review. College Student Journal, 46(4), 823-828.

Polhill, J. B. (2007). Improving retention in a stem field with a major specific one-credit course for first year students. Louisiana Association of Teachers of Mathematics, 4(2), 1-10. http:/ / www2.southeastern .edu/orgs/LATM/Vol4Num2/retention.pdf

Provasnik, S., \& Planty, M. (2008). Community colleges: Special supplement to the condition of education 2008 (NCES 2008-033). National Center for Education Statistics, Institute of Education Sciences, U.S. Department of Education. http://nces.ed.gov/ pubs2008/2008033.pdf

Raby, R. L., Friedel, J. N., \& Valeau, E. J. (2013). A discussion on community colleges and global counterparts completion policies. Community College Journal of Research and Practice, 40(11), 961964.

https:/ / doi.org/10.1080/10668926.2015.1108253

Reyes, M. E. (2011). Unique challenges for women of color in STEM transferring from community colleges to universities. Harvard Educational Review, 81(2), 241-26 https://doi.org/10.17763/haer.81.2. $324 \mathrm{~m} 5 \mathrm{t} 1535026 \mathrm{~g} 76$

Saldaña, J. (2016). The coding manual for qualitative researchers. SAGE.

Santagata, R., König, J., Scheiner, T., Nguyen, H., Adleff, A. K., Yang, X., \& Kaiser, G. (2021). Mathematics teacher learning to notice: A systematic review of studies of video-based programs. ZDMMathematics Education, 1-16. https://doi.org/ $10.1007 /$ s11858-020-01216-Z

Scott, T. P., Thigpin, S. S., \& Bentz, A. O. (2015). Transfer learning community: Overcoming transfer shock and increasing retention of mathematics and science majors. Journal of College Student Retention: Research, Theory \& Practice, 19(3), 300-316. https:/ / doi.org/10.1177/1521025115621919

Sherin, M. G., \& Van Es, E. A. (2009). Effects of video club participation on teachers' professional vision. Journal of Teacher Education, 60(1), 20-37. https: / / doi.org/10.1177/0022487108328155

Smith, E. J. (2016). Doing science while black. Science, 353(6307), 1586-1586. https://doi.org/10.1126/ science.353.6307.1586

Stage, F., \& Maple, S. (1996). Incompatible goals: Narratives of graduate women in the mathematics pipeline. American Educational Research Journal, 33(1), 23-51. https://doi.org/10.3102/00028312033 001023

Styhre, A. (2011). The architect's gaze: The maintenance of collective professional vision in the work of the architect. Culture and Organization, 17(4), 253-269. https:/ / doi.org/10.1080/14759551.2011.590304

Thoma, A, \& Nardi, E. (2017). Transition from school to university mathematics: Manifestations of unresolved commognitive conflict in first year students' examination scripts. International Journal of Research in Undergraduate Mathematics Education, 4(1), 166-180. https:/ / doi.org/10.1007/ s40753-0170064-3

Townsend, B. K., \& Wilson, K. (2006). “A hand hold for a little bit": Factors facilitating the success of community college transfer students to a large research university. Journal of College Student Development, 47(4), 439-456. https://doi.org/10. 2190/CS.10.4.a

Yin, R. K. (2016). Qualitative research from start to finish. The Guilford Press.

Yosso, T. J., Smith, W. A., Ceja, M., \& Solórzano, D. G. (2009). Critical race theory, racial microaggressions, and campus racial climate for Latina/o undergraduates. Harvard Educational Review, 79(4), 659-690. https://doi.org/10.17763/haer.79.4.m686 $7014157 \mathrm{~m} 7071$

\section{https://www.ejmste.com}

